\title{
ANALISIS KINERJA ALGORITMA HONEY ENCRYPTION DAN ALGORITMA BLOWFISH PADA PROSES ENKRIPSI DAN DEKRIPSI
}

\author{
Sujacka Retno(1), Novia Hasdyna ${ }^{(2)}$ \\ Program Studi Magister Teknik Informatika \\ Fakultas IImu Komputer dan Teknologi Informasi \\ Universitas Sumatera Utara \\ e-mail : (1) sujackaretno@students.usu.ac.id, \\ (2) novia hasdyna@students.usu.ac.id
}

\begin{abstract}
Abstrak
Algoritma Honey Encryption dan algoritma Blowfish merupakan dua buah algoritma kriptografi yang dapat digunakan dalam proses enkripsi dan dekripsi. Honey Encryption merupakan salah satu algoritma yang masih baru dalam ilmu kriptografi, untuk itu perlu dilakukan analisis kinerja algoritma tersebut pada proses enkripsi dan dekripsi. Berdasarkan studi perbandingan yang telah dilakukan diperoleh hasil bahwa jika ditinjau proses enkripsi dan dekripsinya, algoritma Honey Encryption jauh lebih efektif dan efisien dibandingkan dengan algoritma Blowfish dari segi keamanan dan tingkat kompleksitas enkripsi dan dekripsinya.
\end{abstract}

Kata Kunci : Kriptografi, Algoritma Honey Encryption, Algoritma Blowfish, Enkripsi, Dekripsi.

\section{PENDAHULUAN}

Perkembangan teknologi informasi telah menyebabkan perubahan dan cara pandang hidup manusia maupun suatu organisasi. Berbagai organisasi, perusahaan, atau pun pihak-pihak lain telah memanfaatkan teknologi basis data untuk menyimpan dan mengelola data organisasi atau perusahaannya. Dibutuhkan sebuah metode penyandian, ilmu sekaligus seni guna menjaga file yang disebut juga dengan kriptografi. Salah satu perangkat lunak kriptografi adalah Pretty Good Privacy (PGP) yang juga bisa digunakan secara online maupun offline. Selain dapat mengamankan file, perangkat lunak ini juga dapat memberikan tanda tangan digital (digital signature) yang mampu memenuhi tiga aspek keamanan yaitu integritas data, otentikasi, dan nirpenyangkalan.

Blowfish adalah cipher block berkunci yang didesain oleh Bruce Schneier pada tahun 1993 yang mencakup jumlah besar cipher dan 
enkripsi. Blowfish memberikan hasil enkripsi yang baik (sulit untuk dipecahkan) dan sampai saat ini belum ada kriptanalisis yang mengklaim telah dapat memecahkannya. Hal tersebut mungkin dikarenakan sistem enkripsi lain yang lebih banyak mendapat perhatian seperti sistem yang terbaru saat ini, Honey Encryption. Teknik Honey Encryption dikembangkan oleh Ari Juels, mantan kepala ilmuwan RSA, dan Thomas Ristenpart dari University of Wisconsin. Honey Encryption paling cocok dalam situasi di mana data terenkripsi diperoleh dari kata sandi. Untuk mengoptimalkan performa maksimal kedua algoritma (Honey Encryption dan Blowfish), ukuran data akan digunakan sebagai pembanding terhadap waktu proses algoritmA karena panjang data adalah sangat penting untuk aplikasi teks, dan perlu diketahui untuk aplikasi yang mendukung plaintext yang panjang seperti aplikasi email atau yang membatasi panjang plaintext seperti aplikasi SMS, manakah enkripsi yang lebih baik performanya.

Hasil dari perbandingan kedua algoritma dapat digunakan sebagai acuan data dua algoritma enkripsi yang populer saat ini, juga dapat digunakan programmer untuk memilih algoritma enkripsi mana yang sesuai dengan aplikasi yang dikembangkan, selain itu dapat juga digunakan sebagai bahan referensi penelitian yang berkaitan dengan algoritma enkripsi Honey Encryption dan Blowfish.

\section{METODE PENELITIAN}

Metode yang digunakan dalam penelitian ini meliputi studi literatur, perancangan, implementasi obyek penelitian, pengujian, pengolahan data uji, dan terakhir pengambilan kesimpulan.

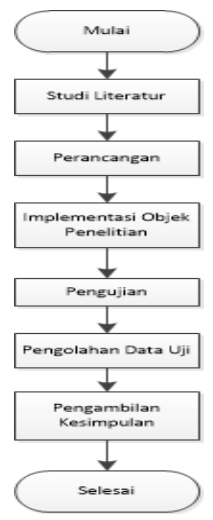

Gambar 1. Metode Penelitian

DOI: https://doi.org/10.29103/techsi.v10i2.858 


\section{HASIL DAN PEMBAHASAN}

\subsection{Skema Enkripsi dan Dekripsi Algoritma Honey Encryption}

\subsubsection{Enkripsi}

Umpamakan A dan B adalah dua pihak yang berkomunikasi, di mana A ingin mengirim pesan M ke B. Dalam proses enkripsi, pengguna akan memberikan pesan (M) dan kunci simetrik (k). Pesan ditempatkan di ruang pesan yang akan dipetakan ke nilai hash dari pesan (S) yang dihasilkan menggunakan logika SHA256. Ruang juga berisi beberapa string valid yang dipilih secara acak (M1, M2, M3, ..) yang dipetakan ke nilai seed (S1, S2, S3,...).

Nilai kunci dihashkan menggunakan SHA256 dengan nilai (R) yang dihasilkan secara acak. Nilai seed ini dienkripsi dengan kunci public dari penerima $\mathrm{B}$ dan digabungkan dengan nilai xor dari nilai yang dipetakan pesan $S$ dan nilai hash kunci dan (R).

$$
\mathrm{C}=\mathrm{H}(\mathrm{K}, \mathrm{R}) \oplus \mathrm{S}|| \mathrm{RSA}(\mathrm{Pub}, \mathrm{R})
$$

Gambar di bawah ini mewakili keseluruhan proses enkripsi yang dilakukan oleh pengirim.

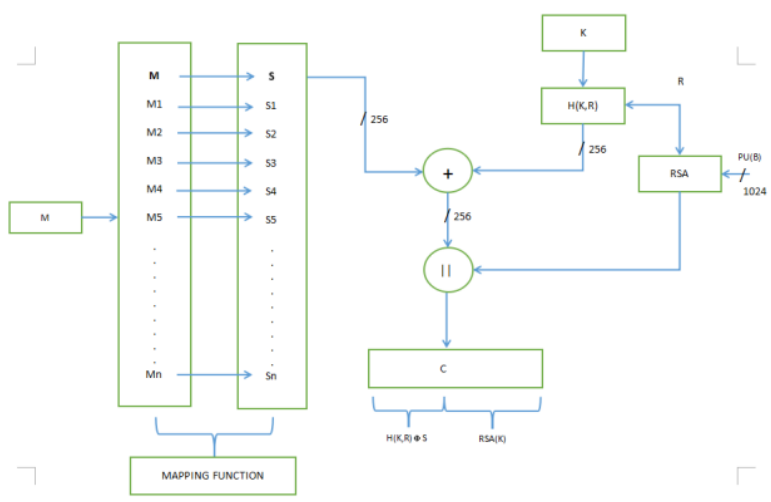

Gambar 2. Proses Enkripsi Honey Encryption

\subsubsection{Dekripsi}

Dalam ciphertext yang dihasilkan oleh pengirim pertama 256 bit memiliki nilai xor, nilai hash kunci dan string acak yang terenkripsi RSA. Pertama di bagian penerima, sebagian RSA diambil dari teks sandi dan didekripsi dengan kunci publiknyauntuk mendapatkan string acak R. 


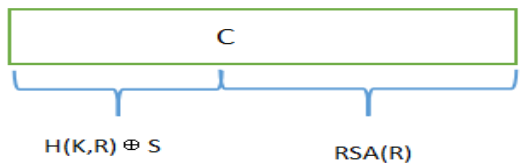

Kemudian penerima akan menggeneratekan nilai hash dengan menggunakan kunci simetrik $\mathrm{K}$ dan mendekripsi string acak $\mathrm{R}$. Lalu, nilai yang dihasilkan adalah nilai xor dengan 256 bit pertama dari ciphertext. Hasilnya nanti akan menghasilkan nilai yang akan dipetakan secara reverse untuk mendapatkan pesan yang dihasilkan.

$$
\mathrm{H}(\mathrm{K}, \mathrm{R}) \oplus \mathrm{S} \oplus \mathrm{H}(\mathrm{K}, \mathrm{RSA}(\mathrm{PRb}, \mathrm{RSA}(\mathrm{Pub}, \mathrm{R})))=\mathrm{S}
$$

Gambar di bawah ini mewakili keseluruhan proses dekripsi pesan.

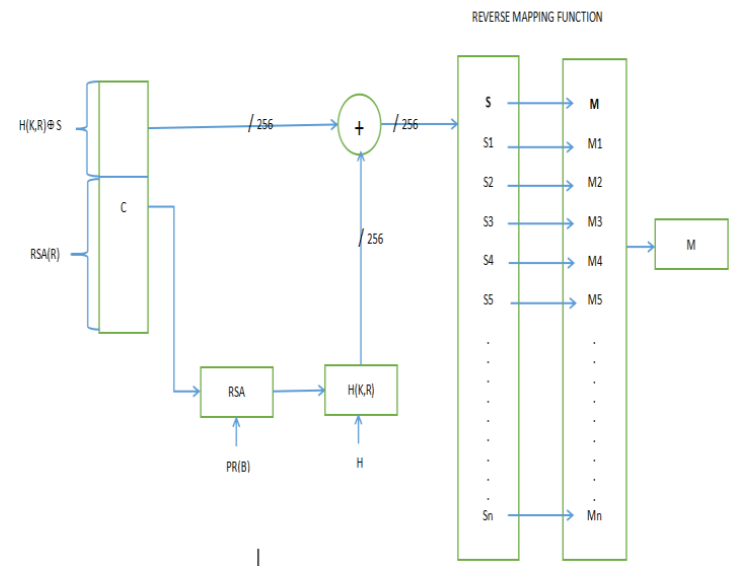

Gambar 3. Proses Dekripsi Algoritma Honey Encryption

\subsubsection{Ketentuan Khusus}

a. Nilai (R) harus mengandung minimal 10 karakter yang mencakup huruf besar, huruf kecil dan bilangan bulat.

b. Dalam perhitungan nilai hash, total jumlah putaran minimal 100000.

c. Kata sandi yang sering digunakan seperti ' 12345 ', 'password', dll digunakan untuk nilai kunci $\mathrm{K} 1, \mathrm{~K} 2, \mathrm{~K} 3, \ldots$ sehingga mudah untuk memanipulasi cryptanalist. 
d. Jika pengirim menggunakan kunci $\mathrm{K}$ yang berada dalam nilai kunci K1, k2, K3, .. maka nilai seed yang diperoleh dengan nilai $\mathrm{K}_{\mathrm{i}}$ harus diperbarui dengan nilai yang diperoleh oleh $\mathrm{K}$.

\subsection{Skema Proses Enkripsi dan Dekripsi Algoritma Blowfish}

Algoritma Blowfish menggunakan kunci simetris dalam proses enkripsi dan dekripsi. Misalkan kunci yang digunakan untuk proses enkripsi adalah ABC. Maka untuk melakukan dekripsi harus menggunakan kunci yang sama yaitu $\mathrm{ABC}$, agar didapati hasil yang sama sebelum dienkripsi. Adapun skema proses enkripsi dan dekripsi pada algoritma Blowfish, dapat di lihat pada gambar dibawah ini.

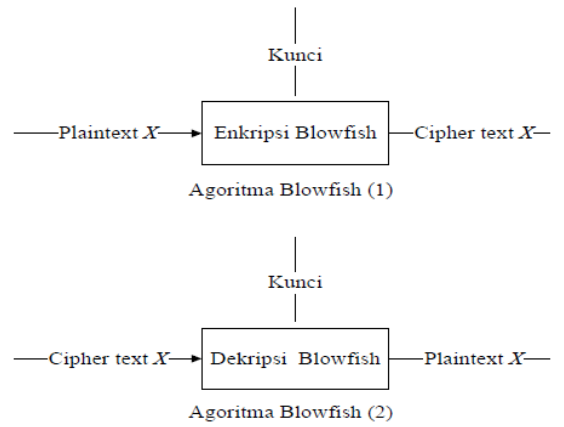

Gambar 4. Proses Enkripsi dan Dekripsi Algoritma Blowfish

Adapun alur algoritma enkripsi dengan metode Blowfish dijelaskan sebagai berikut :

1. Bentuk inisial P-array sebanyak 18 buah (P0,P1,..............P17) masing-masing bernilai 32-bit. Array P terdiri dari delapan belas kunci 32-bit subkunci P0,P1,.......,P17.

2. Bentuk S-box sebanyak 4 buah masing-masing bernilai 32-bit yang memiliki masukan 256. Empat 32-bit S-box masing-masing mempunyai 256 masukan:

$$
\begin{aligned}
& \mathrm{S} 1,0, \mathrm{~S} 1,1, \ldots \ldots \ldots \ldots \ldots \ldots . ., \mathrm{S} 1,255 \\
& \mathrm{~S} 2,0, \mathrm{~S} 2,1, \ldots \ldots \ldots \ldots \ldots \ldots \ldots . ., \mathrm{S} 2,255 \\
& \mathrm{~S} 3,0, \mathrm{~S} 3,1, \ldots \ldots \ldots \ldots \ldots \ldots . ., \mathrm{S} 3,255 \\
& \mathrm{~S} 4,0, \mathrm{~S} 4,1, \ldots \ldots \ldots \ldots \ldots \ldots \ldots . ., \mathrm{S} 4,255
\end{aligned}
$$

3. Plaintext yang akan dienkripsi diasumsikan sebagai masukan, Plaintext tersebut diambil sebanyak 64-bit, dan apabila kurang dari 64-bit maka kita tambahkan bit-nya, supaya dalam operasi nanti sesuai dengan datanya. 
4. Hasil pengambilan tadi dibagi 2, 32-bit pertama disebut $\mathrm{XL}, 32-$ bit yang kedua disebut XR.

5. Selanjutnya lakukan operasi $X L=X L$ xor Pi dan $X R=F(X L)$ xor $\mathrm{XR}$

6. Hasil dari operrasi diatas ditukar $\mathrm{XL}$ menjadi $\mathrm{XR}$ dan $\mathrm{XR}$ menjadi XL.

7. Lakukan sebanyak 16 kali, perulangan yang ke-16 lakukan lagi proses penukaran XL dan XR.

8. Pada proses ke-17 lakukan operasi untuk $\mathrm{XR}=\mathrm{XR}$ xor $\mathrm{P} 16$ dan $\mathrm{XL}=\mathrm{XL}$ xor P17.

9. Proses terakhir, satukan kembali $\mathrm{XL}$ dan $\mathrm{XR}$ sehingga menjadi 64-bit kembali.

\section{KESIMPULAN}

1. Aplikasi pengamanan data menggunakan algoritma Honey Encryption dan Blowfish mempunyai dua teknik pembacaan yaitu teknik enkripsi (mengubah file asli menjadi file yang tidak dapat dibaca) dan teknik dekripsi (mengubah file yang tidak dapat dibaca menjadi file asli).

2. Aplikasi pengamanan algoritma Honey Encryption mempunyai kalimat sandi yang mempadukan sandi yang umum digunakan dan dipadukan dengan huruf besar dan kecil dibedakan, agar sulit ditebak oleh para cryptanalyst.

3. Honey Encryption lebih unggul dalam tingkat keamanan data dibandingkan dengan Blowfish karena memiliki tingkat yang lebih kompleks sehingga memungkinkan para cryptanalyst terkelabuhi dengan hasil yang didapatkan ketika mencoba menyerangnya.

\section{DAFTAR PUSTAKA}

Nahri Syeda Noorunnisa, and Dr. Khan Rahat Afreen, "Review on Honey Encryption Technique", IJSR, Volume 5 Issue 2, February 2016, 1683-1686.

Rifkie Primartha, "Penerapan Enkripsi dan Dekripsi File Menggunakan Algoritma Data Encryption Standard (DES)" JSI, Volume 3, No. 2, Oktober 2011, 371-387.

Santhi Baskaran, S.V.L Sarat Chandra, P.Venkatesh, E.Silambarasan, and M. Dinesh, "Implementation of Enhanced Honey Encryption for IoT Security", IJNTR, Volume-3, Issue-3, March 2017, 87-89. 
Taufiqur, Rahman Muhammad., Aryo Pinandito, dan Eko Sakti Pramukantoro, "Perbandingan Performansi Algoritme Kriptografi Advanced Encryption Standard (AES) dan Blowfish pada Text di Platform Android" Jurnal Pengembangan Teknologi Informasi dan Ilmu Komputer, Volume 1, No 12, Desember 2017, 1551-1559. 